\title{
Impactos de usinas hidrelétricas sobre os recursos pesqueiros amazônicos: os casos de Tucuruí e Belo Monte
}

\author{
Kaio Diego das Neves Barros ${ }^{1^{*}}$ (D), Marcos Ferreira Brabo² (D), Antônio Carvalho Ferreira ${ }^{3}$ (D) \\ ${ }^{1}$ Laboratório de Genética Aplicada, Universidade Federal Rural da Amazônia, Avenida Presidente Tancredo Neves, \\ 2501, Bairro Montese, Belém, PA, Brasil, 66077530. \\ 2 Instituto de Estudos Costeiros, Universidade Federal do Pará, Alameda Leandro Ribeiro, SN, Aldeia, Bragança, PA, \\ Brasil, 68600000. \\ ${ }^{3}$ Grupo Rosana Barros, Av. Gov. Magalhães Barata, 557, Nazaré, Belém, PA, Brasil, 66825020. \\ * Autor para correspondência: kaio.diegobarros@gmail.com
}

Recebido em 15 de abril de 2020.

Aceito em 24 de novembro de 2020.

Publicado em 31 de dezembro de 2020.

Resumo - As usinas hidrelétricas (UHE) produzem parcela significativa da energia elétrica consumida no Brasil e espera-se aumentar o número desses empreendimentos para atender à crescente demanda. Contudo, a severidade dos impactos sobre a biodiversidade e à população nativa pode inviabilizar seu custo-benefício. $\mathrm{O}$ maior potencial brasileiro para aproveitamento hidroelétrico está na Amazônia, bioma onde a atividade pesqueira apresenta um relevante papel na socioeconomia, na produção de alimento e na geração de atividade remunerada. Neste contexto, a UHE de Tucuruí e, mais recentemente, a UHE de Belo Monte são experiências emblemáticas de alterações significativas na dinâmica da atividade pesqueira e dos estoques. Assim, podem balizar a mitigação de impactos por meio da definição de compensações e o estabelecimento de condicionantes para licenças ambientais de empreendimentos futuros e até aos já instalados, além de nortear a elaboração de planos de manejo para unidades de conservação. Este estudo realizou levantamento dos impactos resultantes da construção das UHE de Tucuruí e Belo Monte sobre os recursos pesqueiros em sua área de influência. Em Tucuruí, os efeitos foram sintetizados a partir de mais de 30 anos de informações disponíveis, enquanto que em Belo Monte enfatizou-se as exigências em termos de condicionantes e compensações do processo de licenciamento ambiental.

Palavras-chave: Amazônia; impactos ambientais; pesca continental; rio Tocantins; rio Xingu.

\section{Impacts of hydroelectric plants on amazon fishery resources: the cases of Tucuruí and Belo Monte}

Abstract - Hydroelectric plants (HPP) generate a significant portion of the electricity consumed in Brazil and the number of these projects is expected to increase to meet the growing demand. However, the severity of impacts on biodiversity and the native population can make its costefficiency unviable. The greatest Brazilian potential for hydroelectric exploitation is in the Amazon, a biome where a fishing activity has a relevant socioeconomic role for food production and generation of remunerated activity. Therefore, the Tucuruí HPP and most recently the Belo Monte HPP are emblematic experiences of change in the dynamics of fishing activity and fish stocks. They can guide the mitigation of impacts through the definition of compensations 
and the establishment of conditions for licenses environmental impacts of future projects and even those already installed, in addition to guiding the preparation of management plans for conservation units. This study surveys the compacted impacts of the construction of the Tucuruí and Belo Monte HPP on the fishing resources in its influence area. In Tucuruí, the effects were synthesized from more than 30 years of available information, while in Belo Monte the requirements in terms of conditions and compensations of the environmental licensing process were emphasized.

Keywords: Amazon; environmental impacts; freshwater fishing; Tocantins River; Xingu River.

\section{Impactos de las plantas hidroeléctricas en los recursos pesqueros amazónicos: los casos de Tucuruí y Belo Monte}

Resumen - Las plantas hidroeléctricas (UHE) producen una porción significativa de la electricidad consumida en Brasil y se espera aumentar el número de estos proyectos para satisfacer la creciente demanda. Sin embargo, la severidad de los impactos sobre la biodiversidad y la población nativa puede hacer inviable su costo-beneficio. El mayor potencial brasileño para la explotación hidroeléctrica se encuentra en la Amazonía, un bioma donde la actividad pesquera juega un papel socioeconómico relevante para la producción de alimentos y la generación de actividad remunerada. En este contexto, la UHE de Tucuruí, y más recientemente la UHE de Belo Monte, experiencias emblemáticas de cambios significativos en la dinámica de la actividad pesquera y las reservas. De esta manera, pueden orientar la mitigación de impactos a través de la definición de compensaciones y el establecimiento de condiciones para licencias ambientales para proyectos futuros e incluso aquellos ya instalados, además de orientar el desarrollo de planes de manejo para unidades de conservación. En este estudio se realizó un relevamiento de los impactos derivados de la construcción de las UHE de Tucuruí y Belo Monte sobre los recursos pesqueros de su área de influencia. En Tucuruí, los efectos se sintetizaron a partir de más de 30 años de informaciones disponibles, mientras que en Belo Monte se enfatizaron los requisitos en términos de condiciones y compensaciones del proceso de licenciamiento ambiental.

Palabras clave: Amazonía; impactos ambientales; pesca continental; Río Tocantins; Río Xingu.

\section{Introdução}

O termo "matriz energética" define a quantidade de recursos energéticos disponíveis à demanda de uma determinada região ou país e, quanto à energia elétrica, a principal fonte é de usinas termelétricas por meio da queima de combustíveis fósseis. No Brasil predomina a utilização de fontes de energia não renováveis como o petróleo e seus derivados, e além destes, os derivados da cana-de-açúcar, lenha, carvão vegetal e energia hidráulica, que são caracterizados como fontes de energia renováveis (Brasil 2007; ONS 2018).

Nesse interim, a produção de energia elétrica oriunda de usinas hidrelétricas (UHE) ganha destaque ao aproveitar este potencial hídrico da bacia hidrográfica brasileira que engloba cerca de $12 \%$ da água doce do planeta, estando a maior parte presente na Amazônia. Assim, a perspectiva da administração pública é incrementar a presença de projetos desta natureza em território amazônico (Brasil 2017; ONS 2018). 
Tal intenção não é uma discussão recente e gera divergências quanto aos benefícios e impactos, especialmente pela opção de outras fontes de energia comparavelmente de menor impacto e pouco exploradas, como a eólica e a solar. A perda de biodiversidade, a influência no modo de vida de populações nativas e a inundação de extensas áreas habitadas por populações tradicionais, como povos indígenas, representam alguns dos principais efeitos negativos da implantação de hidrelétricas (Tundisi 2007).

Os impactos da construção de usinas hidrelétricas sobre os recursos pesqueiros são imensuráveis e com baixa capacidade de mitigação dada a inevitável interferência em habitats por meio das alterações na qualidade da água provocadas pela transformação de um ambiente lótico em lêntico (Tundisi 2007). Na Amazônia há uma potencialização desses impactos devido à importância da atividade pesqueira na região, isto é, um risco à diversidade de espécies e à economia local por se tratar de atividade tradicional, sustentando a subsistência, o emprego e a renda (Ruffino 2004).

Deste modo, as particularidades do bioma amazônico e a importância da pesca na região tornam fundamental o conhecimento do histórico e da situação atual dos impactos proporcionados sobre esta atividade a montante, no reservatório e a jusante desses grandes projetos. Essas informações podem nortear a mitigação de impactos, as compensações, as condicionantes para licenças ambientais de empreendimentos futuros e até aos já instalados na região, além de subsidiar a elaboração de planos de manejo para unidades de conservação.

Este estudo objetivou abordar os impactos gerados pelas usinas hidrelétricas de Tucuruí e Belo Monte sobre os recursos pesqueiros em suas respectivas áreas de influência.

\section{Material e métodos}

\section{Área de estudo}

UHE de Tucuruí

No estado do Pará, as usinas hidrelétricas mais importantes em termos de geração de energia e de magnitude dos impactos são Tucuruí e Belo Monte. A construção da UHE de Tucuruí se deu entre 1976 e 1984, com o objetivo de atender a demanda por energia elétrica de projetos de mineração instalados na região, em especial do Projeto Grande Carajás, estimular a industrialização e abastecer diversos estados brasileiros. Sua barragem possui extensão de $11 \mathrm{~km}$, altura de 78 metros e está localizada no município de mesma denominação (0349'56”S - 49³8'59”W) (Figura 1), na mesorregião Sudeste do estado do Pará, a cerca de $300 \mathrm{~km}$ em linha reta da capital, Belém (Mérona et al. 2010). 
Figura 1. Localização das usinas hidrelétricas de Tucuruí e Belo Monte no Estado do Pará.

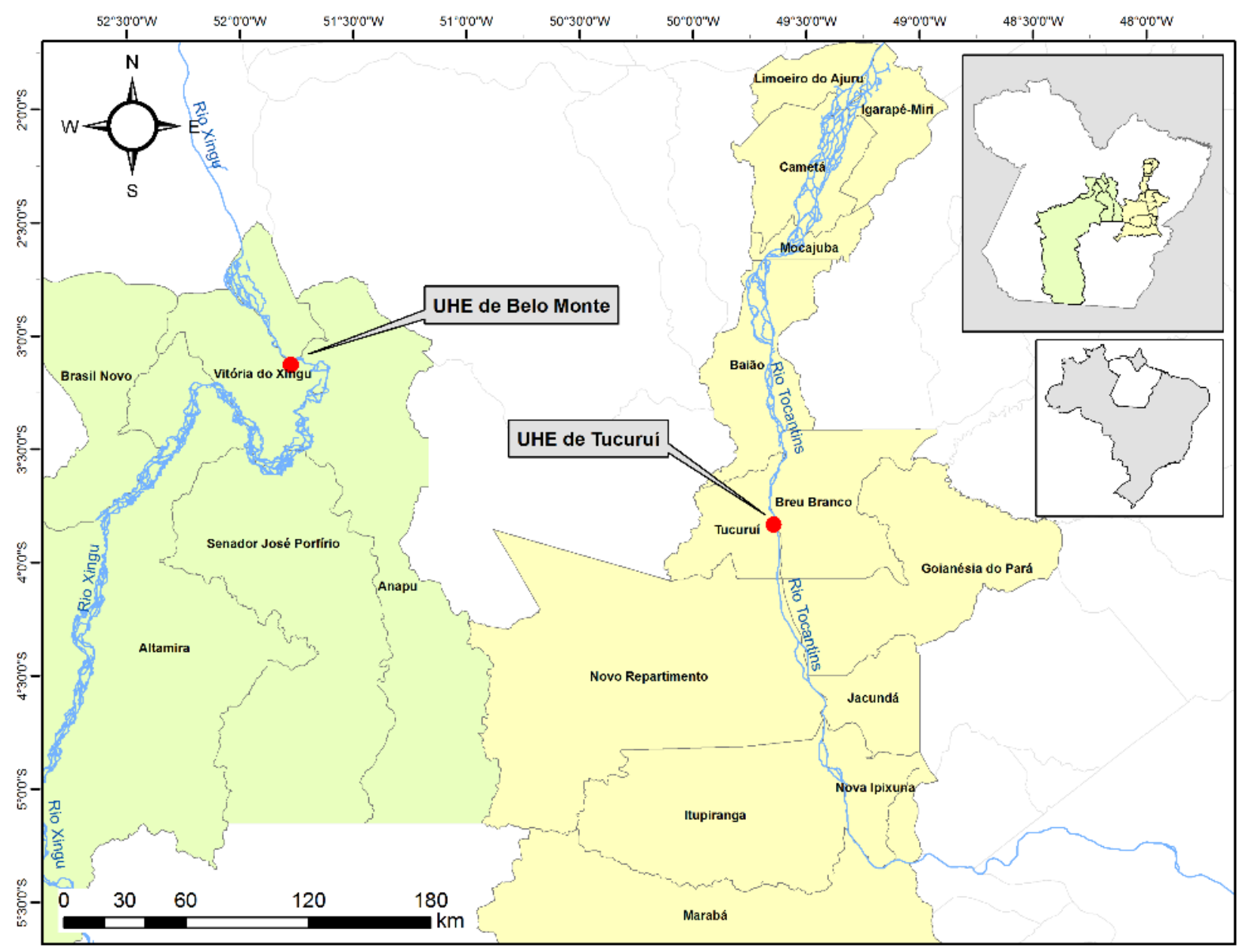

O reservatório formado com o fechamento da barragem em 1984 apresenta aproximadamente $200 \mathrm{~km}$ de extensão, largura média de $14,3 \mathrm{~km}$, área total estimada em $3.513 \mathrm{~km}^{2}$, volume de 50,2 bilhões de $\mathrm{m}^{3}$, perímetro de $6.400 \mathrm{~km}$ e profundidade média de 17,3 metros. Contudo, não há consenso sobre esses dados, com autores afirmando que o comprimento é de apenas $170 \mathrm{~km}$ e a área inundada de $1.430 \mathrm{~km}^{2}$, valores diretamente influenciados pela cota no período da medição. Estima-se que existam entre 1.600 e 1.800 ilhas no reservatório, topos de morros que não foram submersos com a inundação, em sua maioria, habitadas (Sanches e Fisch 2005; CBDB 2018).

A área do reservatório engloba municípios do Sudeste e do Nordeste paraense, são eles: A) montante, formado por Itupiranga $\left(154,9 \mathrm{~km}^{2}\right)$ e Marabá $\left(43,6 \mathrm{~km}^{2}\right)$; 3$)$ reservatório, composto por Tucuruí $\left(621,6 \mathrm{~km}^{2}\right)$, Breu Branco $\left(238,3 \mathrm{~km}^{2}\right)$, Goianésia $\left(546,2 \mathrm{~km}^{2}\right)$, Jacundá $\left(342,5 \mathrm{~km}^{2}\right)$, Nova Ipixuna $\left(124,9 \mathrm{~km}^{2}\right)$ e Novo Repartimento $\left(1441,3 \mathrm{~km}^{2}\right)$; e 4) jusante, constituída por municípios que compõe a área de influência, como Baião, Mocajuba, Cametá, Limoeiro do Ajuru e IgarapéMiri (Figura 2A) (Cintra 2009). 
Figura 2. Vista aérea das barragens das Usinas Hidrelétricas de Tucuruí (A) e Belo Monte (B), Amazônia, Brasil.
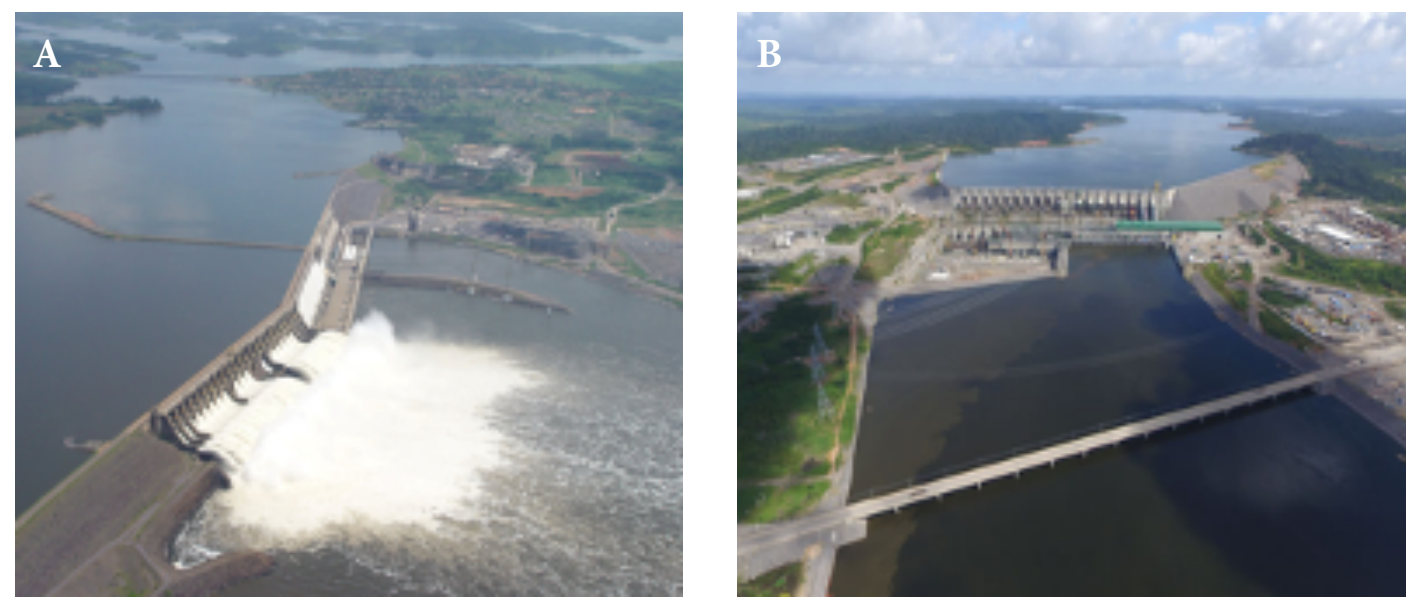

Fonte: Cintra (2009) e Norte Energia (2018), respectivamente.

\section{UHE de Belo Monte}

A construção da Usina Hidrelétrica de Belo Monte em Altamira-PA foi idealizada na década de 1980, com vistas principalmente ao atendimento da demanda energética de projetos de mineração, mas teve sua construção iniciada apenas em 2011, após extensas negociações com ambientalistas e povos indígenas da região, que culminaram em uma significativa diminuição do escopo da obra. Sua barragem principal está localizada no município de Vitória do Xingu (0312’10”S 52¹2’21”W), na mesorregião Sudoeste do estado do Pará (Norte Energia 2018) (Figura 1).

Esta usina apresenta dois reservatórios com área total de $516 \mathrm{~km} 2$, o principal no Sítio Pimental e o intermediário na região da Volta Grande do Xingu, além de um canal de derivação de $20 \mathrm{~km}$ de comprimento, $300 \mathrm{~m}$ de largura média e $25 \mathrm{~m}$ de profundidade. A área de inundação abrange os municípios de Altamira $\left(267 \mathrm{~km}^{2}\right)$, Vitória do Xingu $\left(248 \mathrm{~km}^{2}\right)$ e Brasil Novo $\left(0,5 \mathrm{~km}^{2}\right)$; e os municípios de Senador José Porfírio e Anapu estão sob sua área de influência direta a montante e a jusante, respectivamente (Figura 2B) (Ladislau et al. 2016; Norte Energia 2018).

\section{Coleta de dados}

Esta revisão bibliográfica teve como objetivo abordar os impactos ambientais sobre os recursos pesqueiros gerados pela construção das usinas hidrelétricas de Tucuruí e Belo Monte. Estes projetos constam entre os três maiores do Brasil desta natureza com produção de 8.535 e 11.233 MW, respectivamente, perdendo apenas para a binacional UHE de Itaipu (14000 MW).

Assim, o levantamento bibliográfico foi realizado por meio das ferramentas de pesquisa online Google Acadêmico e Science Direct, e os termos de pesquisa utilizados foram: "usinas hidrelétricas", "UHE”, “impactos ambientais", "atividade pesqueira”, "pesca artesanal”, “Tucuruí", "Belo Monte”, "impactos na pesca”, "recursos pesqueiros”, "diminuição de estoques”, "depleção de recursos", "área de inundação", "produção pesqueira", "espécies de peixes", "peixes nativos”, "espécies endêmicas" e "área de influência”. Para compor as referências deste estudo, foram considerados documentos com até 20 anos de publicação, com exceção de alguns documentos com data de publicação mais antiga. 


\section{Resultados e discussão}

\section{Impactos de usinas hidrelétricas sobre os recursos pesqueiros amazônicos}

Até o século XIX, a demanda por energia elétrica no Brasil era atendida basicamente por usinas termelétricas e pequenas centrais hidrelétricas de abrangência regional. Contudo, a intensificação dos processos de urbanização e industrialização ocorrida ao longo do século XX motivou o investimento em usinas hidrelétricas de maior abrangência, especialmente na segunda metade com a inauguração de Três Marias-MG em 1962, Furnas-MG em 1963, Ilha Solteira-SP em 1973, ItaipuPR e Tucuruí-PA em 1984 (Brabo et al. 2014).

Neste período, as exigências legais em relação aos possíveis impactos ambientais proporcionados por esses empreendimentos eram brandas ou inexistentes, o que culminou em severos danos à fauna, à flora e à população residente em sua área de influência. Dentre os principais efeitos da implantação pode-se ressaltar a decomposição de vegetação inundada e a consequente emissão de gases de efeito estufa, como o dióxido de carbono $\left(\mathrm{CO}_{2}\right)$ e o metano $\left(\mathrm{CH}_{4}\right)$; problemas de saúde pública, principalmente pela dispersão de vetores de doenças; desapropriação de terras; deslocamento de comunidades; e o comprometimento ou perda de atividades produtivas em ecossistemas terrestres e aquáticos (Tundisi 2007; Fearnside 2019).

Quanto à estas atividades, a pesca assume papel de destaque. De maneira geral, os efeitos da construção de hidrelétricas sobre os recursos pesqueiros são: alterações por sucessão ecológica, como a diminuição da diversidade e aumento de populações naturais de ambientes lênticos a montante, motivadas por incremento da área, de alimento e do esforço de pesca; ressalta-se também a significativa diminuição na densidade dos estoques pesqueiros a jusante, especialmente por prejuízos a migrações reprodutivas e tróficas (Agostinho et al. 2007).

$\mathrm{Na}$ Amazônia, apesar do propagado potencial hidrelétrico, a predominância é de rios de planície e isso, até poucas décadas, demandou a inundação de extensas áreas para uma eficiente geração de energia, como UHE Balbina. Atualmente, há uma tendência ao uso de hidrelétricas do tipo "fio d'água" em que a estrutura é construída próxima à superfície e utiliza turbinas para aproveitar a velocidade do rio para gerar energia, o que, em teoria, demanda menor área inundável e causa menor impacto, como por exemplo, na UHE Belo Monte (Junk e Mello 1990; Fonseca et al. 2016). Segue uma breve apresentação das principais UHE da Amazônia e seus impactos, no entanto, como objetivo desse artigo, maior ênfase é dada a Tucuruí e Belo Monte pelas suas extensões e possíveis impactos.

A Usina Hidrelétrica de Balbina localizada no rio Uatumã, no estado do Amazonas, entrou em operação no ano de 1989. Seu reservatório apresenta uma área de $2.360 \mathrm{~km}^{2}$ e sua formação promoveu um significativo incremento na produção pesqueira local, em especial de tucunarés (Cichla spp.), explorados com fins comerciais e esportivos até os dias de hoje (Santos e Oliveira Júnior 1999). Quanto aos impactos negativos, além dos efeitos na diversidade da ictiofauna, a maior crítica sobre este empreendimento é pela extensa área alagada frente à baixa capacidade de produção de energia, o que torna questionável o seu custo benefício e levou alguns estudiosos a considerarem essa construção o maior desastre ecológico premeditado do Brasil (Fearnside 2014).

Quanto à Usina Hidrelétrica de Samuel, situa-se no rio Jamari, em Rondônia, seu reservatório apresenta $656 \mathrm{~km}^{2}$ e foi plenamente cheio também em 1989. Estudos da ictiofauna pré e pósenchimento do lago artificial apontaram que houve diminuição na diversidade de espécies e 
aumento na biomassa de piranha preta (Serrasalmus rhombeus), tucunaré (Cichla monoculus), aracu comum (Schizodon fasciatus) e mapará (Hypophthalmus edentatus). Na jusante, houve incremento da população de mandi (Pimelodus blochii) e de peixes de hábito piscívoro, enquanto detritívoros e frugívoros diminuíram consideravelmente (Santos 1995).

As usinas hidrelétricas de Jirau e Santo Antônio foram construídas no rio Madeira, estado de Rondônia, tiveram suas obras finalizadas no ano de 2016 e contam com reservatórios com áreas de $361,6 \mathrm{~km}^{2}$ e $422 \mathrm{~km}^{2}$, respectivamente. O impacto sobre os recursos pesqueiros promovidos por esses empreendimentos ultrapassou as escalas regionais e nacionais, visto que este curso d'água apresenta relevante importância na produção de pescado de outros países, como o Peru e a Bolívia. A dourada (Brachyplatystoma rousseauxii) foi a espécie que teve o estoque mais comprometido com a concepção dessas hidrelétricas, visto que sua migração reprodutiva foi significativamente prejudicada (Nogueira e Magalhães 2016; Silva e Paula 2018).

No tocante à Usina Hidrelétrica de Coaracy Nunes, situada no rio Araguari, estado do Amapá, a geração de energia elétrica para a região teve início em 1975. Seu reservatório é o mais antigo da Amazônia, tem área de $23,5 \mathrm{~km}^{2}$ e, atualmente, a atividade pesqueira é praticada principalmente com fins de subsistência. Contudo, entrevistas com pescadores que vivenciaram o período prébarramento sugerem a existência de uma notável abundância de espécies de grande porte nesta época, inclusive de algumas que não apresentam mais ocorrência no local, além de uma maior densidade dos estoques pesqueiros (Oliveira et al. 2013).

A Usina hidrelétrica de Curuá-Una foi inaugurada em 1977 no rio de mesmo nome, no estado do Pará, visando atender a demanda energética de municípios da mesorregião do Baixo Amazonas, em especial de Santarém. Seu reservatório hidráulico possui cerca de $75 \mathrm{~km}$ de comprimento e $4 \mathrm{~km}$ de largura, o que totaliza uma área de $300 \mathrm{~km} 2$. Em termos de impactos sobre os recursos pesqueiros foi observada diminuição na diversidade de espécies, predominância de carnívoros no reservatório e superioridade numérica de herbívoros e onívoros em trechos de ambiente lótico (Vieira 2000).

\section{UHE de Tucuruí e os impactos sobre os recursos pesqueiros}

$\mathrm{Na}$ área de influência da UHE de Tucuruí, no rio Tocantins, a dinâmica da pesca mudou drasticamente, com irreversível prejuízo aos municípios localizados a jusante da barragem, principalmente Baião, Mocajuba, Cametá, Limoeiro do Ajuru e Igarapé-Miri (Figura 1), onde a depleção dos estoques pesqueiros comprometeu severamente o modo de vida da população, que vive basicamente do extrativismo (Bentes et al. 2014). Segundo Santos et al. (1984), antes da concepção da obra, a pesca já fazia parte do cotidiano de todos os municípios citados, sendo praticada com fins de subsistência e comerciais, mesmo que em pequena escala. A publicação "Catálogo de peixes comerciais do baixo rio Tocantins”, editada em 1984 pelas Centrais Elétricas do Norte do Brasil (ELETRONORTE), Conselho Nacional de Desenvolvimento Científico e Tecnológico (CNPq) e Instituto Nacional de Pesquisas da Amazônia (INPA), indicou a ocorrência de 300 espécies neste período, com predominância de Characiformes, Siluriformes e Perciformes da família Cichlidae, dos quais 50\% apresentavam valor comercial.

Quanto aos Characiformes, os Prochilodontidae jaraqui (Semaprochilodus sp.) e curimatã (Prochilodus sp.) eram as espécies de maior valor e relevância em termos de preço e volume 
desembarcado, sendo caracterizados pela acentuada ocorrência a montante, hábito migratório e formação de cardumes, o que tende a facilitar a captura. Semaprochilodus brama e Prochilodus nigricans representavam as principais espécies de jaraqui e curimatã, respectivamente. Além deles, a branquinha (Curimata spp.) e a ubarana (Anodus elongatus) eram representantes frequentes da composição de captura de pescarias da região (Santos et al. 1984).

Dentre os siluriformes, os pimelodídeos tinham os volumes desembarcados mais significativos, principalmente o mapará (Hypophthalmus marginatus). No que diz respeito aos representantes da família Pimelodidae, a dourada (Brachyplatystoma flavicans) e o filhote (Brachyplatystoma filamentosum) eram as principais espécies consideradas de grande porte e que efetuavam migrações no início da vazante (abril a junho) e da enchente (novembro a janeiro) e que resultavam em picos de produção pesqueira a jusante. O surubim (Pseudoplatystoma fasciatum) e a pirarara (Phractocephalus hemiolipterus) também eram recursos pesqueiros importantes nesta área (Santos et al. 1984).

No tocante aos Cichlidae, os tucunarés (Chicla ocellaris) e (Chicla temensis) eram as principais espécies, habitando lagos e margens dos rios. Esses peixes apresentavam acentuada importância econômica e eram capturados principalmente na região de Itupiranga. Jacundás e acarás também tinham papel relevante na região, com destaque para os gêneros Crenicichla e Cichlassoma, respectivamente (Santos et al. 1984).

Segundo Cintra (2009), após cerca de 30 anos da construção da barragem, é consenso afirmar que os principais impactos na ictiofauna local da área de influência desse empreendimento foram: estabelecimento de populações de iliófagos a montante, como o jaraqui (Semaprochilodus sp.) e o curimatã (Prochilodus sp.), e aumento da abundância de peixes que se alimentam no reservatório e sobem o rio Tocantins para reproduzir; incremento na biomassa das populações de peixes carnívoros e planctófagos na área do reservatório, como o tucunaré (Cichla sp.) e o mapará (Hypophthalmus edentatus); e diminuição na biomassa dos estoques de espécies comerciais a jusante, como o mapará e os grandes bagres, filhote (Brachyplatystoma filamentosum) e dourada (B. rousseauxii).

As principais espécies capturadas no reservatório e a montante da Usina Hidrelétrica de Tucuruí são: o mapará (H. edentatus), o tucunaré (Cichla sp.), a pescada branca (Plagioscion squamossissimus), a jatuarana escama grossa (Hemiodus unimaculatus) e os acarás (Acaronia nassa, Acarichthys heckelli, Mesonuta festivus, Caquetaia spectabilis, Chaetobranchus flavescens e Aequidens tetramerus). A jusante tem o mapará e o camarão amazônico (Macrobrachium amazonicum) como recursos pesqueiros prioritários (Cintra et al. 2007; Cintra 2009).

Apesar da estatística pesqueira ser extremamente falha, o incremento na produção de pescado do reservatório pode ser balizado pelo município de Tucuruí, que apresentava um desembarque de 452 toneladas antes do barramento e teve um volume desembarcado de cerca de 5.000 toneladas em 2001. O desembarque a jusante da usina foi de 1.118 toneladas em 1981, caiu para 186 toneladas em 1986 e chegou a 439 toneladas em 1999, com tendência a manutenção nos anos posteriores (Juras et al. 2004). A falta de dados atualizados dificulta tirar melhores conclusões acerca da produção, embora a estatística seja um compromisso assumido nas condicionantes das renovações da licença de operação do empreendimento.

Atualmente, a gestão dos recursos pesqueiros na região perpassa também pelo mosaico de unidades de conservação criado no reservatório pela Lei Estadual n ${ }^{\circ} 6.451$ de 8 de abril de 2002, com as seguintes áreas: Área de Proteção Ambiental do Lago de Tucuruí (568.667 hectares); Reserva de Desenvolvimento Sustentável Alcobaça (36.126 hectares); e Reserva de Desenvolvimento Sustentável 
Pucuruí-Ararão (29.049 hectares); além de duas Zonas de Proteção da Vida Silvestre (Áreas de Soltura 3 e 4) (Pará 2002; Pinheiro et al. 2016). Na jusante, o município de Baião conta com a Reserva Extrativista Ipaú-Anilzinho criada pelo Decreto Federal SN de 14 de junho de 2005 (Brasil 2005).

No tocante à legislação pesqueira, o principal instrumento regulador é a Instrução Normativa Interministerial MPA/MMA n 13 de 25 de outubro de 2011 (Brasil 2011a). Esta norma jurídica define o período de defeso no reservatório de novembro a fevereiro, quando é permitida a captura de pescado apenas para consumo próprio, bem como considera pesca ilegal: uso de redes de arrasto de qualquer natureza, qualquer apetrecho fixo com função de bloqueio, mergulho com aparelhos de respiração artificial, uso de aparelhos luminosos ou sonoros, eletricidade, substâncias tóxicas, explosivos, entre outros (Pinheiro et al. 2016).

Além do período de defeso e da proibição e restrição quanto ao uso de apetrechos e artes de pesca, o tamanho mínimo de captura para algumas espécies de peixes é utilizado como medida de ordenamento na bacia hidrográfica do rio Tocantins (Tabela 1), o que abrange a área de influência do reservatório (Brasil 2011a; Pinheiro et al. 2016).

Tabela 1. Tamanho mínimo de captura dos peixes no reservatório da Usina Hidrelétrica de Tucuruí, estado do Pará, Amazônia, Brasil.

\begin{tabular}{ccc}
\hline Nome vulgar & Nome científico & Tamanho mínimo de captura (cm) \\
\hline Aruanã & Osteoglossum bicirrhosum & 50 \\
Barbado & Pinirampus pirinampu & 50 \\
Bargada & Sorubimichthys planiceps & 80 \\
Cachorra & Hydrolicus scomberoides & 50 \\
Caranha & Piaractus brachypomus & 40 \\
Cumimatã & Prochilodus nigricans & 25 \\
Sarda & Pellona castelnaeana & 25 \\
Filhote & Brachyplatystoma filamentosum & 100 \\
Jaú & Zungaro zungaro & 80 \\
Mandubé & Ageneiosus inermis & 35 \\
Mapará & Hypophthalmus marginatus & 29 \\
Matrinxã & Brycon gouldingi & 30 \\
Pescada branca & Plagioscion squamossissimus & 32 \\
Piau cabeça gorda & Leporinus trifasciatus & 30 \\
Piau flamengo & Leporinus fasciatum & 20 \\
Pirarara & Phractocephalus hemiolipterus & 80 \\
Pirarucu & Arapaima gigas & 155 \\
Tucunaré & Cichla spp. & 35 \\
Surubim & Pseudoplatystoma fasciatum & 80 \\
\hline
\end{tabular}

Fonte: Brasil 2011a. 
Outro recurso pesqueiro que merece destaque na área de influência da hidrelétrica, em especial a jusante, é o camarão da Amazônia (Macrobrachium amazonicum), também conhecido como camarão sossego, camarão canela, camarão cascudo ou camarão-regional. Na região, a exploração comercial desta espécie é efetuada por pescadores artesanais, principalmente com auxílio de armadilhas de madeira denominadas de "matapi" (Costa et al. 2016).

A comercialização do camarão ocorre geralmente nas próprias residências dos responsáveis pela captura, sendo levada por intermediários à sede dos municípios ou aos centros urbanos mais próximos, onde os preços praticados tendem a ser melhores. Essa espécie é responsável, também, pela subsistência e complemento de renda de um significativo número de famílias que residem nas margens dos rios e têm o extrativismo pesqueiro e vegetal como meio de sustento (Costa et al. 2016).

Por fim, as maiores demandas do setor pesqueiro na região são: levantamentos confiáveis de estatística pesqueira; melhoria da infraestrutura dos principais pontos de desembarque e comercialização; aumento das ações de educação ambiental e fiscalização, no sentido de inibir a pesca predatória; recadastramento dos pescadores profissionais e regularização das embarcações pesqueiras, para maior controle do esforço; e políticas públicas eficientes de fomento à aquicultura (Brabo 2013).

\section{UHE de Belo Monte e os impactos sobre os recursos pesqueiros da região}

Antes da usina, a pesca na região era caracterizada como ornamental, de subsistência e artesanal. A pesca ornamental era baseada em acaris (Loricaridae), arraias (Potamotrygonidae) e acarás (Cichlidae), com destaque para o endêmico acari zebra (Hypancistrus zebra), o amarelinho (Baryancistrus xanthellus), o picota ouro (Scobinancistrus aureatus), a arraia de fogo preta (Potamotrygon leopoldi), o acará disco (Symphysodon spp.) e o acará bandeira (Pterophyllum scalare). As pescarias artesanal e de subsistência exploravam principalmente as espécies de peixes apresentadas na Tabela 2.

Tabela 2. Espécies de peixes explorados pela pesca de subsistência e artesanal na área de influência da Usina Hidrelétrica de Belo Monte, estado do Pará, Amazônia, Brasil.

\begin{tabular}{cc}
\hline Nome vulgar & Nome científico \\
\hline Ariduia ou jaraqui & Semaprochilodus brama \\
Curimatá & Prochilodus nigricans \\
Flexeira ou jatuarana & Hemiodus unimaculatus \\
Matrinxã & Brycon cephalus \\
Pacu & Myleus spp. \\
Pescada & Plagioscion spp. \\
Piau & Leporinus spp. \\
Piranha & Serrasalmus spp. \\
Pirarara & Phractocephalus hemiolipterus \\
Surubim & Pseudoplatystoma fasciatum \\
Traíra & Hoplias malabaricus \\
Trairão & Hoplias sp. \\
Tucunaré & Cichla spp.
\end{tabular}

Fonte: Adaptado de Magalhães et al. (2016). 
$\mathrm{Na}$ área de influência da UHE de Belo Monte, rio Xingu, a discussão acerca da implantação do empreendimento elencou também a possível extinção de espécies de peixes endêmicos, alguns explorados pela pesca ornamental. Por ser obra mais recente, as exigências em termos de estudos, mitigação e reparação de impactos foram significativamente maiores do que em Tucuruí, tanto que o empreendimento conta com uma escada de peixes para viabilizar a piracema. Ainda assim, a mortalidade de peixes e a influência negativa na dinâmica da pesca, praticada inclusive pela população nativa, são problemas recorrentes (Magalhães et al. 2016; Fainguelernt 2019).

$\mathrm{Na}$ época, de acordo com os estudos desenvolvidos para ictiofauna realizados no âmbito do processo de licenciamento ambiental da usina, algumas espécies de peixes, inclusive endêmicas e de distribuição muito restritas, poderiam desaparecer ou ter seus estoques diminuídos sensivelmente, como consequência das mudanças previstas nos ciclos hidrológicos. Outras espécies poderiam sofrer extinções locais por falta de condições ecológicas para sua sobrevivência, em especial a perda da amplitude do pulso de inundação e a destruição de habitats. Já que os impactos influenciariam na mudança da estrutura trófica da comunidade e na abundância relativa das diversas espécies, assim como na diversidade como um todo (Brasil 2011b).

Esse cenário já foi registrado em outros empreendimentos hidroelétricos, inclusive na Amazônia, e a condicionante para a licença foi a mesma de experiências anteriores, um Programa de Conservação da Ictiofauna para monitorar os efeitos sobre os organismos aquáticos e propor soluções a curto, médio e longo prazo no sentido de mitigá-los. No entanto, o estudo de impacto ambiental previu as consequências como graves à atividade pesqueira, com aumento da produção nas áreas dos reservatórios e prejuízo considerável na região da Volta Grande (Brasil 2011b).

O referido programa de conservação da ictiofauna abrange seis projetos, denominados de Projeto de Monitoramento da Ictiofauna, Projeto de Investigação Taxonômica, Projeto de Incentivo a Pesca Sustentável, Projeto de Aquicultura de Peixes Ornamentais, Projeto de Implantação e Monitoramento de Mecanismo de Transposição, e Projeto de Resgate e Salvamento da Ictiofauna. Conta, ainda, com um uma proposta para estudos de viabilidade para a implantação de parques aquícolas nos reservatórios do Xingu e intermediário (Brasil 2011b).

De acordo com Norte Energia (2019), nos últimos sete anos estes projetos têm contribuído com para a mitigação dos impactos no meio natural causados pela implantação das hidrelétricas, com destaque para a inédita reprodução em cativeiro do acari zebra Hypancistrus zebra, peixe de grande relevância econômica para a atividade ornamental; a soltura de aproximadamente 4 milhões de filhotes de tartaruga da Amazônia Podocnemis expansa; monitoramento de espécies; e conservação de sítios de reprodução natural.

Em termos de mitigação dos impactos ambientais, o mecanismo adotado para transposição de peixes na Usina Hidrelétrica de Belo Monte merece evidência (Figura 4), uma escada de peixes com cinco metodologias de monitoramento: sistema de vídeo, microchips de identificação animal, biotelemetria, capturas dentro e fora do canal (manejo) e relação da vazão do canal com a passagem de peixes. Esta tecnologia é utilizada no Brasil e também em outros países, como a França (Brasil 2011b; Tractebel 2018; Coelho 2019). 
Figura 4. Sistema de transposição de peixes na Usina Hidrelétrica de Belo Monte, estado do Pará, Amazônia, Brasil.

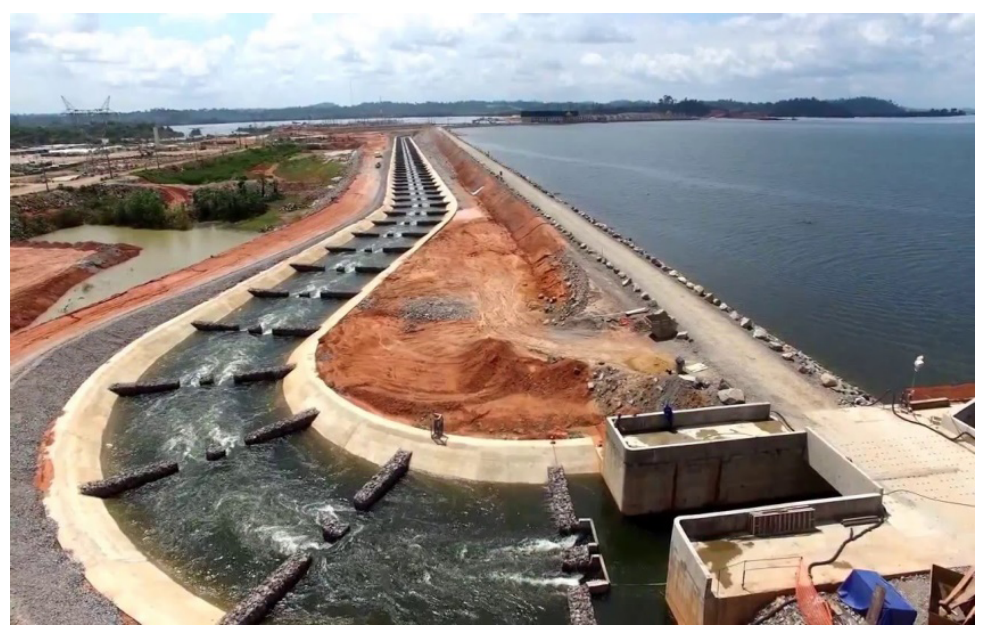

Fonte: Norte Energia 2018.

Assim, em relação à Usina Hidrelétrica de Belo Monte pode-se observar que a atividade pesqueira não representou um fator limitante para a tomada de decisão acerca da obra, mesmo cientes da influência sobre espécies endêmicas de peixes. A ausência de informações sobre as espécies e sua ecologia, assim como da importância dos recursos pesqueiros para a população local, fez com que primeiro se construísse e depois houvesse um monitoramento dos efeitos, para assim definir compensações.

\section{Considerações finais}

Apesar de ser considerada uma fonte de energia mais sustentável do que a de origem vegetal, as usinas hidrelétricas de Tucuruí e Belo Monte promoveram impactos que comprometeram a biodiversidade aquática e o modo de vida de populações nativas. Dentre os principais podemos destacar as alterações limnéticas, como o fluxo e qualidade de água; interferência sobre a migração de espécies, como a piracema, que prejudicaram de algum modo a reprodução; destruição de hábitats naturais para reprodução e alocação de espécies endêmicas; interferência sobre os estoques pesqueiros e consequentemente a produção pesqueira local.

Apesar disso, as hidrelétricas citadas desenvolveram e têm perpetuado ações no intuito de mitigar os efeitos nocivos de suas implantações, tais como: projetos com a participação da sociedade civil e academia para monitoramento, reprodução, manejo e conservação de espécies e hábitats; uso de ferramentas que permitem a migração de peixes no sentido à montante (escada de peixes); entre outros.

Considerando que a população que reside na região amazônica apresenta um dos maiores consumos per capita de pescado do mundo e tem a pesca como umas de suas atividades de renda e subsistência, espera-se a matriz elétrica do Brasil apresente soluções mitigadoras de maior efeito sobre os impactos causados ou busque outras fontes de energia menos prejudiciais do ponto de vista ambiental. 
Participação dos autores: KDNB - revisão bibliográfica e redação principal do texto, desenvolvimento do mapa; MFB revisão principal de referências sobre UHE de Tucuruí; ACF - revisão principal de referências sobre UHE de Belo Monte.

Aprovação ética e outras licenças: não se aplica.

Disponibilidade dos dados: os dados coletados não estão depositados em nenhum banco e dados.

Fomento: não houve financiamento.

Conflito de Interesses: não há conflitos de interesse.

\section{Referências}

Agostinho AA, Gomes LC, Pelicice FM. 2007. Ecologia e manejo de recursos pesqueiros em reservatórios do Brasil. Maringá: Editora da Universidade Estadual de Maringá, 501p.

Bentes ES, Santana AC, Almeida OT, Santana AL. 2014. A pesca artesanal a jusante da Usina Hidrelétrica de Tucuruí, estado do Pará. Novos Cadernos NAEA, 17(2):167-187.

Brabo MF, Veras GC, Paiva RS, Fujimoto RY. 2014. Aproveitamento aquícola dos grandes reservatórios brasileiros. Boletim do Instituto de Pesca, 40(1):121-134.

Brabo MF. 2013. Avaliação da sustentabilidade de um parque aquícola continental na Amazônia Oriental brasileira. Universidade Federal do Pará/Universidade Federal Rural da Amazônia/Empresa Brasileira de Pesquisa Agropecuária Amazônia Oriental. Programa de Pós-graduação em Ciência Animal. Tese de Doutorado, 82p.

Brasil. 2007. Matriz energética nacional 2030. Brasília: Ministério de Minas e Energia/Empresa de Pesquisa Energética, 254p.

Brasil. 2017. Conjuntura dos recursos hídricos no Brasil. Brasília: Agência Nacional de Águas, 169p.

Brasil. Decreto SN de 14 de junho de 2005, cria a Reserva Extrativista Ipaú-Anilzinho, no município de Baião, estado do Pará, e dá outras providências. Diário Oficial da União, 2005.

Brasil. Ministério da Pesca e Aquicultura. Instrução Normativa no 13 de 25 de outubro de 2011, estabelece normas gerais à pesca para bacia hidrográfica do rio Tocantins e período de defeso para as bacias hidrográficas dos rios Tocantins e Gurupi. Diário Oficial da União, 2011a.

Brasil. Ministério do Meio Ambiente. Parecer n 52/2011, análise de solicitação de Licença de Instalação da Usina Hidrelétrica de Belo Monte. 2011b.

CBDB. Comitê Brasileiro de Barragens. Disponível em: <http://www.cbdb.org.br/site/bdados.asp?str_cod=353>. Acesso em: 29 out 2018.

Cintra IHA, Juras AA, Andrade JAC, Ogawa M. 2007. Caracterização dos desembarques pesqueiros na área de influência da Usina Hidrelétrica de Tucuruí, estado do Pará, Brasil. Boletim Técnico-Científico do CEPNOR, 7(1):135-152.

Cintra IHA. 2009. A pesca no reservatório da Usina Hidrelétrica de Tucuruí, estado do Pará, Brasil. Universidade Federal do Ceará. Programa de Pós-graduação em Engenharia de Pesca. Tese de Doutorado, 190p.

Coelho MC. 2019. Estudo Hidráulico de Sistemas de Transposição de Peixes em Hidrelétricas no Brasil e na França. Universidade Federal do rio de Janeiro/Curso de Engenharia Civil. Trabalho de Conclusão de Curso, 72p.

Costa DAS, Martins JC, Silva KCA, Klautau AGCM, Cintra IHA. 2016. Seletividade do matapi nas capturas de Macrobrachium amazonicum no Baixo Rio Tocantins, Amazônia, Brasil. Boletim do Instituto de Pesca, 42(2):403-417. 
Fainguelernt MB. 2019. Impactos da Usina Hidrelétrica de Belo Monte: uma análise da visão das populações ribeirinhas das reservas extrativistas da Terra do Meio. Civitas-Revista de Ciências Sociais, 20(1):43-52.

Fearnside PM. 2014. Balbina foi um grande desastre ecológico. Desativá-la não seria a melhor opção? Ciência Hoje, 53(355):5-6.

Fearnside PM. 2019. Hidrelétricas na Amazônia: Impactos ambientais e sociais na tomada de decisões sobre grandes obras. Manaus: INPA, 148p.

Fonseca RO, Borges LRM, Lourenço SC. 2016. Estado, mercado e meio ambiente: uma análise sobre a implantação de usinas hidrelétricas na Amazônia brasileira. Geofronter, 2(1):59-89.

Junk WJ, Mello JASN. 1990. Impactos ecológicos das represas hidrelétricas na bacia amazônica brasileira. Estudos Avançados, 4(8):126-143.

Juras AA, Cintra IHA, Ludovino RMR. 2004. A pesca na área de influência da Usina Hidrelétrica de Tucuruí, estado do Pará. Boletim Técnico-Científico do CEPNOR, 4(1):77-88.

Ladislau JLB, Póvoa MM, Sucupira IMC, Galardo AKR, Damasceno OC, Cardoso BS, Tauil PL. 2016. Malaria control in area of hydroelectric construction on the Amazonian ecosystem can succeed?. Revista Pan-Amazônica de Saúde, 7(1):115-122.

Magalhães SB, Silva YYP, Vidal CL. 2016. Não há peixe para pescar neste verão: efeitos socioambientais durante a construção de grandes barragens. Desenvolvimento e Meio Ambiente, 37(1):111-134.

Mérona B, Juras AA, Santos GM, Cintra IHA. 2010. Os peixes e a pesca no baixo rio Tocantins: 20 anos depois da UHE Tucuruí. Brasília: Centrais Elétricas do Norte do Brasil S.A./Institut de Recherche pour le Development/Instituto de Pesquisas da Amazônia/Universidade Federal Rural da Amazônia, 395p.

Nogueira CR, Magalhães MA. 2016. Os impactos socioeconômicos causados aos pescadores do Médio e Baixo Madeira a partir da construção da Usina Hidrelétrica de Santo Antônio. Revista de Administração e Negócios da Amazônia, $8(2): 279-291$.

Norte Energia. 2018. UHE Belo Monte, a maior usina hidrelétrica 100\% brasileira. Disponível em: <https://www. norteenergiasa.com.br/pt-br/uhe-belo-monte/a-usina>. Acesso em: 29 out 2018.

Norte Energia. 2019. UHE Belo Monte: geração de energia e desenvolvimento sustentável para o crescimento do brasil. Disponível em: <https://www.norteenergiasa.com.br/pt-br/imprensa/uhe-belo-monte-geracao-de-energia-edesenvolvimento-sustentavel-para-o-crescimento-do-brasil-100653>. Acesso em: 15 out 2020.

Oliveira JCS, Vasconcelos HCG, Pereira SWM, Nahum VJI, Teles Júnior AP. 2013. Caracterização da pesca no reservatório e áreas adjacentes da UHE Coaracy Nunes, Ferreira Gomes, Amapá-Brasil. Biota Amazônia, 3(3):83-96.

ONS. Operador Nacional do Sistema Elétrico. 2018. O que é o ONS? Disponível em: <http://ons.org.br/paginas/sobreo-ons/o-que-e-ons>. Acesso em: 06 out 2020.

Pará. Lei nº 6.451 de 8 de abril de 2002, cria Unidades de Conservação da Natureza na região do Lago de Tucuruí no território sob jurisdição do estado do Pará e dá outras providências. Diário Oficial do Estado do Pará. 2002.

Pinheiro JCR, Santos MF, Souza MB. 2016. Orientações sobre a legislação vigente da pesca artesanal no Mosaico do Lago de Tucuruí. Belém: Instituto de Desenvolvimento Florestal e da Biodiversidade, 20p.

Ruffino ML. 2004. A pesca e os recursos pesqueiros na Amazônia brasileira. Manaus: Instituto Brasileiro de Meio Ambiente e Recursos Naturais Renováveis/PróVárzea, 268p.

Sanches F, Fisch G. 2005. As possíveis alterações microclimáticas devido a formação do lago artificial da hidrelétrica de Tucuruí - PA. Acta Amazonica, 35(1):41-50. 
Santos GM, Oliveira Júnior AB. 1999. A pesca no reservatório da Hidrelétrica de Balbina (Amazonas, Brasil). Acta Amazonica, 29(1):145-163.

Santos GM. 1995. Impactos da Hidrelétrica Samuel sobre as comunidades de peixes do rio Jamari (Rondônia, Brasil). Acta Amazonica, 25(3-4):247-280.

Santos JM, Jegu M, Mérona B. 1984. Catálogo de peixes comerciais do Baixo rio Tocantins. Manaus: Centrais Elétricas do Norte do Brasil S.A./Conselho Nacional de Desenvolvimento Científico e Tecnológico/Instituto Nacional de Pesquisas da Amazônia, 84p.

Silva FM, Paula EA. 2018. Usinas hidrelétricas sob os véus da "sustentabilidade": os pescadores artesanais da Ponta do Abunã (RO) e a Usina Hidrelétrica de Jirau. Novos Cadernos NAEA, 21(1):159-178.

Tractebel. 2018. Metodologia inovadora para escada de peixes no Brasil. Disponível em: <https://tractebel-engie.com.br/ pt/noticia/2018/metodologia-inovadora-para-escada-de-peixes-no-brasil>. Acesso em: 06 out 2020.

Tundisi JG. 2007. Exploração do potencial hidrelétrico da Amazônia. Estudos Avançados, 21(59):109-117.

Vieira I. 2000. Frequência, constância, riqueza e similaridade da ictiofauna da Bacia do rio Curuá-Una, Amazônia. Revista Brasileira de Zoociências, 3(2): 51-76. 